\title{
A experiência audiovisual nos espaços educativos: possíveis interseções entre educação e comunicação
}

Eloiza Gurgel Pires

Universidade de Brasília

\section{Resumo}

0 presente trabalho relaciona os campos da comunicação e da educação a partir de uma reflexão sobre a experiência audiovisual no contexto dos espaços educativos. Aponta-se a transversalidade das mídias audiovisuais como um desafio importante para a escola, considerando-se a complexidade do momento histórico em que vivemos e seus processos de construção de subjetividades decorrentes dos novos modos de ler, ver, pensar e aprender. Procuramos encontrar, nas práticas atuais dos espaços de sala de aula, elementos que pudessem fornecer subsídios para aprofundar algumas questões relacionadas ao discurso áudio-imagético dentro de uma perspectiva histórico-cultural, recolocando a questão das poéticas tecnológicas, inserindo a técnica no universo da cultura. Nossa preocupação com relação às referências teóricas para este estudo foi a de não limitar as questões problematizadas nesta investigação a determinados guetos teóricos, sem que, para isso, o objeto de pesquisa sofresse diluições. Assim, trabalhamos com autores que nos ajudaram a transitar por diferentes campos do conhecimento e saberes. Estabelecemos diálogos com o pensamento bakhtiniano; com pesquisadores que estão refletindo sobre as produções audiovisuais contemporâneas; e com autores como José Luiz Braga e Regina Calazans; Martin-Barbero; e David Buckingham que nos permitiram uma visão ampliada sobre a contemporaneidade e as questões significativas dos campos da educação e da comunicação, especialmente as questões relacionadas aos estudos de educação para as mídias.

\section{Palavras-chave}

Educação - Comunicação - Meios audiovisuais - Contemporaneidade. 


\title{
The audiovisual experience in educational spaces: possible intersections between education and communication
}

Eloiza Gurgel Pires

Universidade de Brasília

\begin{abstract}
This work draws relations between the fields of communication and education based on a reflection about the audiovisual experience within the context of educational spaces. The transversal character of the audiovisual media is pointed out as an important challenge for the school, considering the complexity of the historical moment in which we live, and its processes of construction of subjectivities attending new ways of reading, seeing, thinking and learning. We try to find within the current practices in classrooms aspects that could give us elements to examine some of the questions concerning the audio-image discourse under a cultural-historical perspective, repositioning the issue of technological poetics, and inserting technique into the universe of culture. Special care was taken with respect to the theoretical background for this study to avoid limiting the issues problematized in the investigation to certain theoretical ghettos, without, nevertheless, allowing the object of research to become diluted. We have, therefore, worked with authors that helped us to traverse different knowledges and fields of knowledge. We established dialogues with the Bakhtinian thought, with researchers that are reflecting on contemporary audiovisual productions, and with authors such as José Luiz Braga and Regina Calazans, Martin-Barbero and David Buckingham, who gave us a wider view of contemporaneity and of the significant issues in the fields of education and communication, particularly of the questions related to the education studies for the media.
\end{abstract}

\section{Keywords}

Education - Communication - Audiovisual media - Contemporaneity.

Contact:

Eloiza Gurgel Pires 
Nosso sistema escolar construiu, durante um longo tempo, processos interacionais essencialmente baseados no relacionamento face a face e na palavra escrita. No entanto, o século XX ampliou, com as novas tecnologias, o leque de possibilidades de novas integrações direcionadas para diferentes objetivos e processos sociais, o que não poderia deixar de incidir sobre a educação.

Em uma sociedade mediatizada, deparamo-nos não apenas com diferentes "saberes", mas com múltiplas formas de mediação e difusão desses saberes. Consequentemente, são modificados os modos de aprender relativos a esses saberes. Vale ressaltar que, no atual momento civilizatório, a tecnologia não agrega somente novos artefatos e novos modos de fazer, introduz também outra dinâmica em que o tempo e o espaço são reelaborados, produzindo novas formas de relacionamento entre as pessoas. Estas continuam buscando um sentido para sua existência que, para Bakhtin (2003), é encontrado nas relações estabelecidas por intermédio da linguagem, portanto, na comunicação.

Todavia, na relação entre educação e comunicação, é muito comum reduzir o campo da comunicação à sua dimensão instrumental ou ao uso dos meios, deixando escapar algo que seria estratégico: a inserção da educação nos complexos processos comunicacionais da sociedade atual, considerando um sistema difuso de informações, a interseção de linguagens e o descentramento de saberes em relação aos centros da escola e livros que organizam nosso sistema educativo. Para Martin-Barbero (2000), a difusão de conhecimento é uma das questões mais importantes que a comunicação propõe hoje para a educação. Para o autor, no nosso sistema escolar, constata-se que não só existe o preconceito com relação à oralidade cultural, como também com relação à cultura audiovisual: uma atitude defensiva diante do desafio de reconhecer um novo ecossistema comunicativo, no qual emerge outra cultura, com novos modos de ler, ver, pensar e aprender.
Por outro lado, ao relacionar os campos da educação e da comunicação, observamos que o educacional se coloca, inevitavelmente, como uma questão central para as novas interações da comunicação social. Portanto, a cada invenção tecnológica, a sociedade atribui aos processos comunicacionais surgidos dos novos meios uma expectativa educacional, podendo-se afirmar que os dois campos se invadem, estão entrelaçados. José Luiz Braga e Regina Calazans (2001) afirmam que

[...] as preocupações comunicacionais da Educação, e as preocupações sobre aprendizagem na Comunicação, parecem de algum modo penetrar os dois campos originais na sua totalidade e fornecer-lhes novos ângulos e questões para observação. (p. 56)

Aqui, interessa-nos abordar os relacionamentos entre comunicação e educação a partir de uma reflexão sobre a experiência audiovisual nos espaços educativos, apontando a transversalidade das mídias audiovisuais como um desafio importante para a escola, pois, apesar de todas as transformações sociais e tecnológicas da contemporaneidade, um processo de produção audiovisual no espaço escolar induz a interesses e comportamentos que perturbam o seu quadro habitual conformado pelas velhas práticas que há muito tempo atuam com uma racionalização disciplinadora, separando os saberes - idades, o pensar do sentir, o trabalho do ócio. Ao contrário, a cultura midiática não separa o sensível do inteligível; a atividade reflexiva do entretenimento. Desse modo, a produção midiática nos espaços escolares nos remete à dimensão emotiva, ao imaginário e às mitologias da nossa época, introduzindo elementos perturbadores às disciplinas clássicas. É preciso considerar que essa "turbulência" poderá gerar uma renovação. Cabe-nos indagar sobre os processos de apropriação e ressignificação dos códigos audiovisuais nas expressões e manifestações culturais dos espaços educativos, e as novas leituras e escrituras daí advindas. 


\section{A linguagem videográfica}

A dimensão social do conhecimento ocorre na interação do sujeito com os objetos e com outros sujeitos, no confronto, na troca de concepções, ideias, teorias, sentimentos e desejos. Essa interação social, geradora de cultura (conhecimento), torna-se possivel por intermédio da linguagem: "A cultura, que é característica da sociedade humana, é organizada/ organizadora via o veículo cognitivo que é a linguagem" (Morin, 1992, p. 17). Transformamos o invisível em visível por meio da linguagem, que constrói uma visão tátil, um pensamento visível. A palavra transforma-se em ato. Revelamos o mundo e nos revelamos para o mundo.

0 homem cria a si próprio e o mundo em que vive, tornando-se sujeito na linguagem. Ocupa um lugar determinado no espaço e revela o seu modo de ver o outro e o mundo físico que o envolve. Assim, a palavra (pensamento) e o olhar (imaginário) constituem o sentido que conferimos à experiência de estar no mundo. A cultura grega, acentuadamente plástica, não separava o ver do pensar. Eidos, forma ou figura, é termo afim de idea. Em latim, video (eu vejo) e idea. Para os gregos, o conceito de téchne se relacionava ao fazer criativo - poiesis - do homem. Ao contrário do pensamento moderno, homem e tecnologia não eram reconhecidos como opostos, não havendo a possibilidade de conceber o ser humano cindido em sujeito e objeto do conhecimento, como se estivesse retalhado em diferentes componentes de si mesmo. A visão dicotomizada da realidade produzida pela epistemologia clássica afetou nossa sensibilidade teórica e cristalizou alguns conceitos que se formaram a partir da construção de uma espacialidade que determinou o "dentro" e o "fora" no ser. Com o racionalismo mutilador da modernidade, emergem as dualidades mente e corpo, dentro e fora, pensamento e imaginário.

Nos dias atuais, os meios híbridos possibilitaram a criação de imagens falantes e em movimento. Os elementos da linguagem verbal e da linguagem visual podem hoje coexistir num mesmo espaço. No entanto, muitos intelectuais ainda mantêm certa suspeita com relação à imagem e aos novos meios, como se fosse possível separar o imaginário do pensamento. Por outro lado, alguns autores (Philippe Dubois; Machado; Parente; Bellour e outros) põem em questão o aspecto iconoclasta dos discursos sobre a imagem, ressaltando o potencial criativo das subversões poéticas nas explorações dos meios audiovisuais.

O surgimento do vídeo nos anos 1960 provocou uma ruptura sem precedentes no universo das imagens técnicas pelas experimentações e formas de apropriação que esse meio possibilitou. A escrita eletrônica do vídeo instaurou novas formas de linguagens, estéticas próprias das imagens híbridas, pós-cinematográficas (eletrônicas e digitais). Trata-se de uma imagem tecnológica que sempre teve problemas de identidade, pois surge entre o cinema e a imagem infográfica, transitória e marginal entre universos de imagens fortes e bem definidas. Movimenta-se entre a ficção e 0 real, o filme e a televisão, a arte e a comunicação. Foi mais explorado em suas formas pelos artistas (videoarte) e no espaço doméstico (vídeo familiar, vídeo privado, documentário etc.), estando entre as esferas artística e midiática. Ele é objeto e processo, público e privado, pintura e televisão, sem ser um nem outro, ou sendo ambos, com um senso constante do ensaio, da pesquisa, da experimentação, da inovação.

Os modos de criação videográfica relativizaram o modelo narrativo, desenvolvendo uma linguagem, ou estética particular (mas não exclusiva), que põe em jogo questões diferentes daquelas já expostas pelo cinema e, ao mesmo tempo, constituem uma forma que pensa, um estado da imagem. 0 vídeo pensa o que as imagens (todas e quaisquer) são, fazem ou criam:

0 vídeo é o material formal e intelectual no qual se processa a reflexão sobre a, da ou com a televisão. Ou, melhor dizendo, que gera, que inventa, que lhe dá corpo e ideias. Há uma espécie de "potência de pensamento" na e pela imagem que me 
parece existir no coração da forma vídeo. 0 "vídeo" seria então, neste sentido e literalmente uma forma que pensa. Um pensamento da imagem em geral - e não apenas da televisão. (Dubois, 2004, p. 113)

Para Dubois (2004), o vídeo não é o outro da televisão, não é o lado estético que ela não gostaria de assumir, não é a sua contraideologia, mas uma maneira de pensar a televisão com suas próprias formas. Machado (1997) entende que a diferença entre TV e vídeo está na intensidade:

Produzido e difundido fora do circuito televisual, pode investir no aprofundamento da função cultural da televisão, avançando de um lado, na experimentação da linguagem eletrônica, e buscando exprimir, de outro, as inquietações mais agudas dos homens do nosso tempo. Ele executa no domínio da televisão, uma função cultural de vanguarda, no sentido produtivo do termo: ampliar os horizontes, explorar novos caminhos, experimentar novas possibilidades de utilização, reverter a relação de autoridade entre produtor e consumidor, de modo a forçar um progresso da instituição convencional da TV, demasiadamente inibida pelo peso dos interesses que são nela colocados em jogo. (p. 10)

Essa produção qualitativa acaba interferindo na prática cotidiana da TV comercial ou pública, havendo um avanço com a introdução de novas tecnologias e com as práticas alternativas de TV, como as TVs comunitárias, piratas, a cabo etc. Na atualidade, a imagem eletrônica destila outra sensibilidade, colocando-nos novos problemas de representação, abalando antigas certezas, reformulando conceitos estéticos, o que Benjamin detectou em um novo sensorium dos modos de percepção, ao fazer uma análise do cinema e dos novos modos de produção das imagens técnicas nos anos 1930.

0 que chamamos de "linguagem" das formas audiovisuais não pode ser confundido com o sentido que se dá à linguagem verbal. A gramática do vídeo, assim como seu processo de articulação de sentido, é diferente da gramática das mensagens verbais. Não há uma tábua de valores ou gramática normativa que exponha o que se pode e o que não se pode fazer em vídeo, até porque se trata de um meio que possui um sistema híbrido, operando com diversos códigos significantes - do cinema, do teatro, da literatura, do rádio e, atualmente, também da computação gráfica: "o discurso do vídeo é impuro por natureza” (Machado, 2005, p. 190).

0 vídeo surgiu num contexto histórico em que não se acreditava mais em uma "gramática específica” para os meios audiovisuais, pois os códigos videográficos não têm a mesma consistência e estabilidade das linguagens verbais, sendo impossível reduzi-los a um conjunto de regras esquemáticas.

No entanto, o vídeo também é um fenômeno de comunicação, que se dissemina de forma processual e não hierárquica no tecido social, confundindo os papéis de produtores e consumidores, podendo resultar daí um processo de troca e de diálogo não muito comum em outros meios. No entanto, para que haja comunicação, é preciso haver estruturas significantes, que sejam inteligíveis a emissores e receptores. Então, se algo é transmitido pelo vídeo, haverá comunicação se as formas operadas e os modos de articulação forem comuns a todos os envolvidos nesse processo. Ainda que esse algo não possua uma lei ou língua natural, possui uma linguagem ou sistema significante que garante sua inserção como canal de expressão numa sociedade.

0 caráter híbrido do produto videográfico mostra-se mais rico na medida em que se mostra aberto à intervenção do espectador, mesmo na manipulação física dos equipamentos e das fitas. Para Machado, as possibilidades tecnológicas dos novos meios estão em permanente mutação, crescendo na mesma proporção das obras produzidas, sendo importante reconhecer a importância do ato criador que subverte a função da máquina, sua produtividade controlada e que reinventa sua 
função e suas finalidades. Isso é o que redefine nossa maneira de produzir e de nos relacionar com determinado meio.

\section{A linguagem audiovisual como um fato da cultura}

Nos anos 1930, Walter Benjamin (1996) chamava atenção para um novo sensorium nos modos de percepção da realidade na sociedade moderna com a reprodutibilidade técnica da imagem. Em uma comparação, ele confronta o teatro e o cinema como duas experiências distintas de se vivenciar a realidade e de se relacionar com a imagem: o teatro oferece um campo visual que permite ao espectador preservar o caráter ilusionístico da cena, enquanto no cinema a natureza ilusionística está no resultado da montagem. 0 cinegrafista, segundo Benjamin (1996), penetra visceralmente a realidade, enquanto o pintor mantém certa distância da realidade dada e dele próprio. Surgem novos conhecimentos e novas formas de expressar os imaginários.

Nos dias atuais, o modo como nos apropriamos das imagens técnicas pode redefinir os modos de ver e de ser visto, a nossa própria maneira de entender e lidar com os meios, ou de reinventá-los. Cada vez mais um número maior de pessoas tem acesso a celulares e a máquinas fotográficas que filmam, produzem textos; brinquedos eletrônicos que tornam o homem comum uma unidade móvel produtora de informação, de textos, de imagens. 0 sujeito contemporâneo tornou-se espectador e produtor de suas próprias mensagens. Surgiram diferentes espaços e temporalidades a partir do uso da tecnologia do audiovisual nas novas produções de subjetividade, que emergem do uso dos novos meios no espaço doméstico, nas culturas juvenis, no cotidiano das escolas, nas associações comunitárias etc.

A década de 1970, início de 1980, especialmente no Brasil, foi um momento importante para a exploração das imagens videográficas no âmbito da cultura popular. Nesse momento, as câmeras de vídeo começam a ser vendidas a preços populares, sinalizando a intenção dos fabricantes em transformá-las em eletrodomésticos. Havia também a intenção de recuperar o tempo perdido com a ditadura militar, buscando-se, nas populações de excluídos e entre os trabalhadores, novos atores para a construção de uma nova sociedade. São criadas associações, núcleos, centros culturais ou de estudos, que mais tarde iriam se transformar no que conhecemos hoje como organizações não governamentais - as ONGs. Muitas dessas organizações iniciaram produções em vídeo que refletiam uma questão fundamental relacionada a essa mídia: a linguagem e seus usos. A maioria dos movimentos populares que se utilizavam do vídeo foi influenciada pela Pedagogia do Oprimido de Paulo Freire (1970). Nesses projetos, a comunicação popular buscava seus termos nos próprios sujeitos da ação, com a câmera aberta - intervenção feita após a exibição de um vídeo, em que o debate ou intervenção do público é realizado a partir das imagens mostradas ao vivo.

Em 1984, em Olinda, Pernambuco, no Centro Luiz Freire, surge a TV Viva. Uma TV de rua que ia aos bairros da periferia levando programação de vídeo que muitas vezes contava com a participação da população. Em 1986, surge em Nova lguaçu, Rio de Janeiro, a TV Maxambomba, também um experimento de rua, inspirado na TV Viva e em experiências do Chile, investindo na ideia de propor aos moradores dos bairros onde era exibida que produzissem seus próprios programas.

Diferentes processos de comunicação popular surgem nos bairros, nas escolas e nos grupos organizados. Em 1996, é criada a TV Pinel - TV comunitária do Instituto Psiquiátrico Phillipe Pinel, Ministério da Saúde - em Botafogo, Zona Sul do Rio de Janeiro. 0 educador baiano Valter Filé (2000) localiza nessas experiências algumas questões em comum: havia a perspectiva de criação de um espaço de audiência pública e coletiva que recuperasse 0 espaço da praça, das ruas, numa celebração do 
reencontro entre as pessoas e delas com questões relacionadas às suas vidas, às culturas e ao lazer. Outra questão seria o acesso das populações aos meios tecnológicos, experimentando sua linguagem e dando novos sentidos ao seu uso.

No campo da educação, essas questões nos remetem a uma discussão sobre os processos subjetivos, nos quais os jovens não são apenas representados no "discurso/imagem" da mídia, mas se tornam sujeitos de uma narrativa audiovisual atualizada no vídeo. Processos subjetivos ou produção de subjetividade não devem ser entendidos aqui do mesmo modo como propõe o discurso "psi”, mas em consonância com o pensamento de Felix Guattari (1992), entendemos subjetividade como um processo de produção de significados ancorado em referentes humanos, materiais e imateriais, referentes que podem ser encontrados tanto nas tensões geradas pelo capitalismo transnacional como nas manifestações culturais e nas expressões artísticas. 0 autor nos sugere um redimensionamento da subjetividade em instâncias individuais, coletivas e institucionais, sem haver qualquer hierarquia entre elas. Em outras palavras, compreendemos os processos subjetivos não apenas na esfera de uma interioridade psíquica, em instâncias inconscientes ou egóicas, mas dentro de um contexto histórico-político-cultural.

Nesse contexto, a evolução tecnológica, as relações espaço-temporais e a produção de imagens, a cultura massificada e a reprodutibilidade da arte, assim como a mídia hegemoneizada pela televisão são fatores fundamentais para o entendimento da produção da subjetividade contemporânea.

Hoje, verifica-se uma crescente produção audiovisual de jovens veiculada na internet; é possível encontrar projetos de produção de vídeos nas escolas; proliferaram os cursos de cinema e audiovisual. Ao redimensionarem os valores de uma ordem já estabelecida em um mundo concreto, sensível, visível, dinâmico, numa fusão de valores e tradições, os jovens ampliam as possibilidades do olhar. Numa produção midiática, criam representações de seu próprio grupo em suas histórias, como forma de definir identidades e de negociar amizades, o que evidentemente envolve trabalho coletivo. A escola, inevitavelmente, torna-se um espaço para as negociações entre concepções de conhecimento e valores culturais.

As negociações entre professor e aluno concretizam diversas experiências culturais, fazendo da realidade um plano multifacetado, no qual os sujeitos aprendem a pensar o "eu" e o "outro" num processo interativo, aproximando, justapondo os contrários, situando o olhar nas fronteiras. Nesse contexto, a produção audiovisual nos espaços escolares nos remete ao pensamento de que vivemos um momento histórico em que a mídia eletrônica deveria ser encarada - ao contrário daquilo que muitos discursos apocalípticos pregam como um fato da cultura, que exprime nossa complexidade e nossas contradições.

\section{Apropriação da linguagem audiovisual}

As novas propostas curriculares apontam três formas de educação midiática: educar pela, com e para a mídia. Embora apresentadas separadamente, as três perspectivas estão relacionadas na reconfiguração dos espaços escolares e nas relações entre o conhecimento e os sujeitos do conhecimento, sendo o professor um importante mediador.

A perspectiva de educar pela mídia é mais conhecida no meio educacional como Educação a Distância (EAD). Nessa modalidade, torna-se possivel a utilização de diferentes mídias (cursos por correspondência, aulas por rádio, teleaulas e educação on line) na aproximação entre sujeitos e conhecimentos, proporcionando diferentes formas de organização do tempo-espaço do estudo.

A Educação com a mídia já ocorre em muitas escolas, apesar de se considerar a necessidade de uma exploração mais efetiva das variadas potencialidades dos meios. Tal modalidade pressupõe o conhecimento das diversas 
possibilidades desses meios para os processos de ensino e de constituição de novos conhecimentos, valores e atitudes. Trata-se da produção de jornais impressos, revistas, blogs, vídeos etc., tornando-se necessário adequar os meios ao tratamento de um determinado assunto em uma situação específica.

A última perspectiva - educar para as mídias - é a que se apropria de forma crítica de diferentes meios, suas linguagens e estéticas, o que implica experiências voltadas para os seus modos de produção.

Todavia, autores como David Buckingham (2005) advertem que a educação para as mídias - educar e aprender sobre a mídia - não deve ser confundida com ensinar através ou com a mídia, não se tratando, portanto, de tecnologia educacional ou mídia educativa. Pela importância social, cultural e econômica da mídia nas sociedades modernas, ele considera essencial uma educação que possibilite aos jovens uma visão mais ampla do universo midiático, pois meios de comunicação fazem parte do nosso cotidiano, fornecendo-nos "recursos simbólicos" que usamos para conduzir e interpretar nossas relações e definir nossas identidades.

Para o educador e pesquisador Buckingham (2005), a mídia não é uma janela por onde podemos ver os acontecimentos do mundo, mas um espaço que fornece canais por meio dos quais representações e imagens do mundo são comunicadas indiretamente. 0 autor considera como "mídia" todos os modernos meios de comunicação - televisão, cinema, vídeo, fotografia, rádio, publicidade, jornal e revistas, CDs, jogos de computador e Internet, incluindo também o livro por tratar-se de uma "mídia" que nos dá uma versão ou representação do mundo.

Assim como Gonnet (2004), tendo em vista uma combinação dos textos da mídia de diversas linguagens ou formas de comunicação - imagens visuais (paradas ou em movimento), áudio (som, música ou fala) e a linguagem escrita -, Buckingham (2005) concebe uma ideia de alfabetização midiática que envolve necessariamente a leitura e a escrita da mídia, desenvolvendo a compreensão crítica e a participação ativa dos jovens que, além de fazerem seus próprios julgamentos como consumidores da mídia, deverão explorar a linguagem midiática em suas próprias produções.

Numa aventura com câmera e vídeo, os alunos descobrem a necessidade de elaborar roteiros, redigir um fio condutor, escolher lugares para a filmagem, assim como as funções necessárias à produção da obra (filmagem, montagem, sincronização). A respeito dessa descoberta, surgem algumas questões. 0 que suscitam essas ações? Sempre uma forte mobilização. Personalidades se descobrem por meio de outra maneira de conceber a escola. Algumas delas vêm à mente naturalmente: Como traduzir um sentimento em imagens? Como se colocar em face da câmera? Deve-se fazer como na televisão ou tentar inventar outro estilo? (Gonnet, 2004) É certo, entretanto, que os alunos também descobrem com as regras de trabalho produtivo, num contexto coletivo, as responsabilidades que isso implica.

No contexto da educação para as mídias, a produção não é um fim em si. Os jovens se apropriam da linguagem midiática para expressar suas ideias e sentimentos de forma criativa ou por meio da Arte. Usam a mídia também para comunicação, sem reduzir esse fazer a um treinamento técnico, sendo necessário o estabelecimento de uma relação dialógica entre professor e aluno e entre os próprios alunos numa permanente negociação. Há também a preocupação em compreender a linguagem audiovisual não como um sistema fechado, mas processual, por meio do qual são construídas as representações e onde acontecem interações - espaço aberto a múltiplas leituras. 0 aluno é contextualizado como produtor e espectador de sua própria mensagem, visto como sujeito histórico, social e cultural, e não apenas como interlocutor, mas como sujeito criativo, transformador.

0 conceito de "apropriação", também utilizado por Canclini (1998), ao se referir à interação entre elementos de variadas sociedades, sugerindo um diálogo entre as diferenças, deve ser en- 
tendido aqui como formas diferenciadas de interpretação, intervenção criativa, apropriação cultural (Chartier, 1988), e não no sentido de uso de poder ou confisco (Foucault, 1971):

[...] a diversidade das leituras, que não forçam o texto. Distancia-se do sentido que Michel Foucault dava ao conceito quando considerava 'a apropriação social dos discursos' como um dos procedimentos mais importantes através dos quais esses discursos eram confiscados e submetidos, colocados fora do alcance de todos aqueles cuja competência ou posição impedia o acesso aos mesmos. [...] A apropriação, tal como a entendemos, tem por objetivo uma história social das interpretações, remetidas para suas determinações fundamentais (que são sociais, institucionais, culturais) e inscritas nas práticas específicas que as produzem. (Chartier, 1988, p. 26)

Para Chartier (1988), além da noção de “apropriação", a noção de "representação" é fundamental dentro de um contexto sociocultural em que uma determinada realidade é construída, pensada, dada a ler, o que implica uma relação ambígua entre ausência e presença. No caso, a representação é a presentificação de um ausente, que é dado a ver segundo uma imagem, mental ou material, que se distancia do mimetismo puro e simples e trabalha com uma atribuição de sentido. Seria uma versão da realidade, não uma apresentação, mas representação. Todas as representações são simbolicamente mediadas, ou seja, todo conhecimento humano é constituído em todas as suas formas de representações, com suas linguagens, pelos seus processos de significações. Nas representações, podem estar implícitas variadas identificações, entendendo-se "representações" como tradução mental ou material da realidade, formas, imagens, sons, textos etc. que determinam a definição que o sujeito dá a si mesmo e o lugar que ocupa dentro de um sistema de relações, havendo, aí, um "outro", que inclusive pode ser a alteridade do "si mesmo", e que reconhecerá (identificará) as representações que classificam o sujeito socialmente.

Nesse sentido, todo conhecimento humano é uma construção simbólica com seu modelo próprio de articulação, pois cada comunidade estabelece sua sociabilidade, baseada nas próprias linguagens e leituras. Assim, as ideias e as representações figuram no cotidiano, estruturando as percepções, as convivências sociais e os modos de estar no mundo, coletivo e individual.

Diferentes conceituações abrem caminhos analíticos, que oferecem diferentes olhares sobre o movimento das imagens no mundo. As representações, seja na sua dimensão simbólica, seja nas suas formas concretas de manifestação, estão ligadas aos contextos histórico e social. Na sua natureza de produção humana e social, elas têm uma dimensão interna e externa aos indivíduos que percebem e são afetados pelas imagens.

No entanto, se considerarmos também o contexto cultural além dos contextos social e histórico, encontraremos um ponto de convergência entre as representações e as apropriações. Martin-Barbero (2003) chama de "mediações" os lugares ou contextos culturais em que acontecem os processos de apropriação da imagem. Ao propor a análise das mediações, o autor não se limita apenas a analisar as imagens, mas a compreender a maneira como lidamos com elas. Assim, somos deslocados do terreno das representações, das imagens, dos produtos em si mesmos e conduzidos para o terreno da história, da cultura, da experiência, do cotidiano.

Nesse contexto, o embate entre diferentes vozes sociais sugere que não há sentido fora da relação com o outro, ainda que o sujeito seja o outro de si mesmo ou o outro das vozes que circulam o seu discurso. Nesse sentido, Hall (2005) define a identidade como a própria incompletude do sujeito, que se reconhece no olhar do outro: aquilo que, no sujeito, não pode ser visto por ele mesmo é mediado pelo olhar do outro, do seu ângulo de visão. Isto é, 
aquilo que o sujeito não sabe sobre si mesmo se revela na relação com o outro. A construção da consciência que o sujeito tem de si se constitui no modo como ele compartilha o seu olhar com o olhar do outro. Dessa forma, cria-se uma linguagem que permite a comunicação no contexto das relações socioculturais.

Em uma experiência com as câmeras, o olhar das pessoas se expande, buscando novas formas de interlocução e de revelação. Observa-se que a sensação de estranhamento é relatada por quase todas as pessoas que viram a própria imagem reproduzida na tela. A experiência da mediação da imagem técnica proporciona outra visibilidade ao sujeito em relação a si mesmo, desencadeando, paradoxalmente, o sentimento de estranhamento daquilo que lhe é familiar: a sua própria imagem. Ele percebe que há algo não reconhecível em relação a si próprio, podendo, posteriormente, incorporar essa nova imagem, assumindo-a como familiar. Nesse momento, vivencia-se uma experiência de transformação da consciência de si.

A relação entre o sujeito e as possibilidades oferecidas pelas câmeras é também uma relação ambivalente, pois se a sensação de perda de controle da própria imagem e do discurso representa uma ameaça, causando as inibições, a relação com a própria imagem é também algo que seduz.

Nas palavras de Souza (2003), ser visto no vídeo "seduz porque no centro da consciência de sermos sujeitos efêmeros existe o desejo de permanência da nossa própria imagem, da nossa presença no mundo, experiência que agora é recriada pela técnica" (p. 86). A autora afirma que, quando o sujeito se coloca em frente às câmeras, ele sabe que sua imagem se deslocará, ganhando uma existência própria, sendo, posteriormente, retomada por outras pessoas em infinitas interpretações. De modos diversos, esse efeito é também alcançado na apropriação de outras linguagens como, por exemplo, a escrita.

Nos relatos de muitos jovens, é possível perceber que, enquanto alguns se sentem mais à vontade filmando, outros preferem se expor como apresentadores, entrevistados, dançarinos ou contadores de histórias. No momento em que se apropriam dos códigos audiovisuais nas suas criações ou como forma de comunicação, torna-se importante o conhecimento da técnica e da linguagem. Com esse conhecimento, estabelecem diferentes formas de se relacionarem com as câmeras, com o mundo, com eles mesmos e com o outro. Nesse relacionar-se, surge a sedução pela própria imagem que, como disse Souza (2003), é a expressão do desejo de permanência dessa imagem no mundo. Entretanto, é também aquilo que Maffesoli (2004) considerou como o "perder-se no outro", ao se referir a um reencantamento do mundo favorecido pela tecnologia, acentuado pelo renascimento da imagem como um importante elemento do vínculo social. Quando as pessoas se veem no vídeo, essa imagem está situada fora e diante de si. Portanto, elas veem a outro, relacionam-se com a dimensão alteritária de si mesmas.

No espelho, as imagens são invertidas, vê-se a simultaneidade dos gestos e há uma confusão entre aquele que está na imagem e o próprio sujeito. Para Bakhtin (2003), nossa situação diante do espelho é sempre um pouco falsa, pois como não dispomos de um enfoque de nós mesmos de fora, recorremos a outro possível e indefinido, que nos ajudará a encontrar uma posição ou uma forma para nós mesmos. Nossa relação com a imagem externa, segundo ele, diz respeito, inicialmente, não à estética, mas ao seu eventual efeito sobre os outros. Assim, avaliamo-nos não para nós mesmos, mas para os outros e por meio dos outros: posamos diante do espelho, procurando a expressão que nos parece ser a ideal, essencial e desejada. Trata-se da construção de diversas vozes sociais ou olhares, que costuram a nossa imagem externa. Os "outros" de que fala Bakhtin, aqueles com quem nos relacionamos, são constituintes do nosso imaginário, na representação que fazemos de nós mesmos. Nas telas audiovisuais, a imagem é captada pela lente de uma câmera manipulada por alguém 
que, através do seu olhar, redimensiona o tempo e o espaço vividos, reproduzindo essa imagem em espelhos eletrônicos, que nos trazem informações novas, inusitadas e, às vezes, constrangedoras sobre nós mesmos. A escola adquire, nesse cenário, uma importância estratégica e decisiva dando voz aos novos sujeitos do discurso e potencializando a figura do educador, que de retransmissor de conteúdos converte-se em formulador de problemas, provocando interrogações e possibilitando o diálogo entre culturas e gerações.

\section{Educação midiática e cidadania}

Benjamin (1996) afirma que, nos espaços históricos de tempo e da existência da coletividade humana, modificam-se o modo e a maneira da percepção sensorial, o que, segundo Martin-Barbero (2000), remete-nos a transformações na maneira de nos relacionarmos, de nos reconhecermos e de nos juntarmos. É o que experimentam os mais jovens quando se apropriam das novas linguagens, uma vivência desvalorizada por muitos adultos.

0 vídeo constitui uma ferramenta e um dispositivo pedagógico importante para os adolescentes por sua capacidade de visualizar os próprios conflitos e o dos outros, por sua ludicidade e tecnicidade e por permitir a participação de todos, ainda que alguns se situem atrás da câmera, protegidos da emoção ou do choque de um confronto direto com o outro e/ ou com a sua cultura. Por mais paradoxal que isso possa parecer, é também uma situação que pode se transformar numa abertura em direção ao outro, ou seja, dentro de uma relação dialógica, o eu e o outro veem o mundo de perspectivas diferentes. Isso não significa que estão incomunicáveis, mas em uma experiência audiovisual, de lugares diferentes, uma negociação permanente de produção de linguagem torna-se possível com a mediação da câmera.

Em uma reflexão ampliada, podemos perceber que o cenário em que se constituem e se movimentam os sujeitos sociais é um espa- ço midiatizado, em que as relações, os valores e a consciência se deparam com uma nova ordem cultural, na qual as mídias eletrônicas constituem, segundo Sodré (2002), um novo bios, um novo modo de presença do homem no mundo. A cultura, resultante de um complexo ecossistema comunicativo, atua na construção da realidade social. A mídia é, então, estruturadora de percepções e cognições, atuando sobre as identidades culturais, a educação, o mundo do trabalho, o exercício de cidadania e a percepção do tempo.

Fala-se muito em cidadania. Com frases feitas que saem quase que automaticamente no discurso dos educadores, os jovens "aprendem" o que devem fazer para serem "cidadãos”. Entretanto, será que, em algum momento, a escola desperta neles uma consciência cidadã ou o desejo de ser cidadão? Os alunos imaginam a escola como um espaço seu?

Ser cidadão na contemporaneidade é pertencer a uma coletividade organizada. 0 pertencimento cidadão não é passivo. Pelo contrário, a cidadania implica uma postura ativa, na qual a participação "naquilo que é feito" marca o processo de construção do cidadão. E é no exercício de suas cidadanias que os indivíduos, a partir dos seus pertencimentos, criam novas formas de ação para atuar no espaço coletivo, recuperando a noção de comunidade (Quiroga, 2002).

A diversidade e a pluralidade marcam a condição de pertencimento e a reflexibilidade do indivíduo contemporâneo. A construção da cidadania como processo social mais amplo implica, entre outras coisas, considerar as comunidades e as esferas mais privadas como espaços sociais dos indivíduos, de construção de identidades, acolhendo as diferenças sociais e culturais pelo que elas representam, por seu dinamismo e riqueza social.

A emergência de um novo paradigma para a educação dentro de um ambiente midiatizado pode ser detectado no pensamento de educadores e pesquisadores que, contrariamente à ideia do jovem como simples vítima passiva das influências da mídia, acreditam que 
a educação pode ser um processo instigante de descoberta de novas atuações e de participação cidadã. Longe de ser uma forma de proteção, a educação midiática é uma forma de preparação, que desenvolve nos jovens a compreensão e a consciência social de pertencimento dentro de um determinado universo cultural.

Para Buckingham (2005), nessa perspectiva, a produção dos estudantes tem importância significativa, pois é o momento em que suas vozes são ouvidas. Não cabe aos educadores colocarem-se na posição de "legisladores", impondo valores e normas da cultura oficial, pois os jovens estão crescendo numa sociedade heterogênea, multicultural, com diferentes concepções de moral e diferentes tradições culturais que coexistem lado a lado. Vale ressaltar a importância de se questionar, em um processo de produção audiovisual, a "identidade política" forjada por uma educação que enfatiza a racionalidade e uma concepção "realista” de representação, assim como a própria noção de cidadania e de democracia em que estão baseadas.

\section{Algumas considerações}

Para Martin-Barbero (2003), "mais do que meios, a comunicação se faz hoje questão de mediações, isto é de cultura" (p. 20). 0 autor alerta para o surgimento de um imaginário que inaugura "uma nova era do sensível", e que fala culturalmente, não sendo usado apenas como manipulação:

[...] a cumplicidade e interpenetração entre oralidade cultural e linguagens audiovisuais não remetem - como pretende boa parte de nossos intelectuais e nossos anacrônicos sistemas educativos - nem às ignorâncias, nem aos exotismos do analfabetismo, mas a descentramentos culturais que em nossas sociedades estão produzindo os novos regimes de sentir e de saber, que passam pela imagem catalisada pela televisão e pelo computador. (Martin-Barbero, 2000, p. 84)
Com essa concepção, é possível compreender os usos e as apropriações dos meios a partir das mediações: "lugar" ou contexto cultural em que a interação entre a produção midiática e a recepção não acontece apenas na perspectiva de interesses industriais ou estratégias comerciais, mas também a partir de uma trama cultural, nas práticas sociais, no cotidiano das pessoas e nos modos de ver - espaços nos quais são construídas nossas representações identitárias.

Entendendo os valores culturais como construtos de diferentes linguagens, os modos como nos apropriamos das linguagens definem nossa relação com as tecnologias e com os meios de comunicação, que podem ser pensados não apenas na sua dimensão instrumental, utilitária - para ampliar as comunicações -, mas também como suportes para as experimentações artísticas, como formas de entretenimento, enfim, na expressão de sentimentos e saberes.

Os deslocamentos, as contradições e a heterogeneidade temporal e espacial das sociedades nos tempos atuais nos remetem a novos parâmetros para compreender a cultura e a comunicação. 0 objeto do campo da comunicação é, nas palavras de Rüdiger (1998), "uma espécie de mediação cotidiana do conjunto das relações sociais, da difusão das ideias e da formação das condutas que têm lugar na sociedade" (1998, p. 16), ou seja, modos como a sociedade conversa com a sociedade. E segundo o autor, dessa troca, ou conversa, surgem os objetivos comunicacionais, gerando tecnologias midiáticas para ampliar e acelerar as comunicações. José Luiz Braga e Regina Calazans (2001) deixam claro que não são os meios de comunicação que direcionam a sociedade, mas esta quem os determina. Para os autores, a ordem tecnológica da civilização é determinada pela ordem cultural dos significados e valores, evidenciando a importância dos valores culturais de nossas sociedades para uma relação mais humanizada com a tecnologia e, da mesma forma, com os meios de comunicação.

Assim, "o sentido em que se move a tecnologia já não é tanto o domínio da natureza pelas máquinas quanto o desenvolvimento 
específico da informação e da comunicação do mundo com as imagens" (Vattimo, 1990, p. 95). Dessa forma, é possível pensar a imagem na educação não como uma ilustração da escrita, mas como uma forma de produção de conhecimento. E a partir de uma trama tecida com figuras e discursos - imagens e palavras -, constituir-se-á o que chamamos hoje de "ciências humanas". Martin-Barbero (2000) ressalta a importância de um novo paradigma do pensamento para estabelecer uma nova relação entre o discurso (a lógica) e o visível (a forma).

$\mathrm{Na}$ atualidade, o sistema midiático se configura como um conjunto de processos de mediações que vem ampliando e diversificando os modos de interação entre variados "eus" e alteridades com diferentes procedimentos e tecnologias, formando, com o livro e o jornal - já seculares -, um conjunto complexo e diversificado, campo para novas poéticas e para as interações sociais, contextualizadas não apenas dentro de uma relação mídia e usuário, mas também entre setores da sociedade e entre pessoas.

A importância da linguagem como instrumento capaz de desenvolver o pensamento aprofunda-se, em seus aspectos mais amplos, com a apropriação de novas mídias. Estabelece-se um diálogo entre a imagem e o discurso, apesar de, durante muito tempo, em nome da razão, a tradição positivista de nossa educação ter valorizado a linguagem escrita como única forma de legitimar os pensamentos, as ideias, enfim, os saberes, não reconhecendo outros códigos - visual, oral, audiovisual - como formas de leitura e escritura do mundo. $\mathrm{Na}$ reinvenção do conhecimento, olhamos o mundo com os olhos do poeta - o arquiteto da linguagem, segundo Décio Pignatari (1988). E “escrevemos com boniteza", como propõe Paulo Freire (1970, p. 201).

A relação dos jovens com as novas tecnologias é, para Martin-Barbero (2000), uma relação de cumplicidade cognitiva e expressiva, pois nos sons, na velocidade, nas imagens e fragmentações, é que os jovens encontram o seu ritmo e o seu idioma. Assistem, hoje, à configuração de uma espacialidade que não se baseia mais nas diferenças entre interior e exterior - espacialidade própria das telas da TV e do computador. 0 autor chama atenção para o descentramento produzido pela televisão na cena doméstica, ressaltando o fato de que as crianças estão mais próximas do mundo dos adultos e de que isso causa certa desordem nas sequências de aprendizagem: as crianças agora "sabem demais" e vivem coisas que "não são para sua idade" (p. 89).

Ao ser acusada de todos os males que cercam a vida dos jovens, a televisão desvela as transformações sociais da contemporaneidade a partir do deslocamento das fronteiras entre razão e imaginação, saber e informação, natureza e artifício, arte e ciência, saber científico e senso comum. E das representações e práticas sociais, em especial as juvenis, emerge uma nova subjetividade, abrindo espaço para um pensamento que não opõe escola e televisão, educação e comunicação (Maffesoli, 2004).

Se, nos anos 1930, W. Benjamin associava as modificações do aparato perceptivo do transeunte no tráfego da grande urbe com a experiência do espectador de cinema, hoje, as transformações que atravessam o sensorium urbano são experienciadas no espaço doméstico por meio da televisão e do computador. Diferentemente das culturas letradas, nos relatos fragmentados do vídeo, do cinema e das culturas eletrônicas audiovisuais, encontramos uma flexibilidade que permite a articulação de elementos de variados mundos culturais, coexistindo lado a lado com diferentes temporalidades.

Estamos vivenciando um momento marcado por mudanças conceituais e metodológicas que a todo instante nos desafiam a compreender nosso papel como educadores e seres humanos criadores de si próprios e do mundo, numa sociedade permeada por tecnologias, denominada às vezes de sociedade da informação, sociedade do conhecimento ou pós-moderna. $\mathrm{Na}$ contemporaneidade, os espaços educativos se deparam com a possibilidade de se apropriarem da cultura midiática para criar novos espaços de 
interação, nos quais alunos e professores tornam-se coautores na construção de conhecimentos, e de estéticas que implicam o reconhecimento do outro - num acontecimento ético.

Nesse contexto, à educação atribui-se o desafio não só de explorar as possibilidades que as novas tecnologias criaram, mas, parafraseando Paulo Freire, de reconhecer, no universo cultural dos jovens e nas telas audiovisuais que fazem parte do seu cotidiano, novos modos de ler (conhecer) o mundo e de escrevê-lo (transformá-lo). Assim, localizamos a escola como uma importante mediadora sociocultural nos processos de apropriação da linguagem audiovisual e usos de diferentes suportes para criação, expressão e comunicação.

\section{Referências bibliográficas}

BAKHTIN, M. Estética da criação verbal. São Paulo: Martins Fontes, 2003.

BENJAMIN, W. Obras escolhidas: magia e técnica, arte e política. São Paulo: Brasiliense, 1996.

BRAGA, J. L.; CALAZANS, R. Comunicação e educação: questões delicadas na interface. São Paulo: Hacker, 2001.

BUCKINGHAM, D. Media education: literacy, learning and contemporary culture. Cambridge: Polity, 2005.

CANCLINI, N. G. Culturas híbridas: estratégias para entrar e sair da modernidade. São Paulo: EDUSP, 1998.

CHARTIER, R. A história cultural: entre práticas e representações. Lisboa: Difel, 1988.

DUBOIS, P. Cinema, vídeo, Godard. São Paulo: Cosac Naify, 2004.

FILÉ, W. (Org.). Batuques, fragmentos e fluxos. Rio de Janeiro: DP\&A, 2000.

FOUCAULT, M. L'ordre du discours. Paris: Gallimard, 1971.

FREIRE, P. Pedagogia do oprimido. Rio de Janeiro: Paz e Terra, 1970.

GUATARRI, F. Caosmose: um novo paradigma estético. Rio de Janeiro: Editora 34, 1992.

GONNET, J. Educação para as mídias. São Paulo: Loyola, 2004.

HALL, S. A identidade cultural na pós-modernidade. Rio de Janeiro: DP\&A, 2005.

MACHADO, A. A arte do vídeo. São Paulo: Brasiliense, 1997.

Pré-cinemas \& pós-cinemas. São Paulo: Papiros, 2005.

MAFFESOLI, M. Notas sobre a pós-modernidade: o lugar faz o elo. Rio de Janeiro: Atlântica, 2004.

MARTIN-BARBERO, J. Novos regimes de visibilidade e descentramentos culturais. In: FlLÉ, W. Batuques, fragmentações e fluxos. Rio de Janeiro: DP\&A, 2000.

Dos meios às mediações. Rio de Janeiro: Editora da UFRJ, 2003.

MORIN, E. 0 método IV - As ideias: a sua natureza, vida, habitat e organização. Portugal: Biblioteca Universitária; Publicações Europa-América, 1992.

PIGNATARI, D. 0 paleolhar da tejevisão. In: NOVAES, A. (Org.). 0 olhar. São Paulo: Companhia das Letras, 1988.

QUIROGA, A. M. A cidadania como indicador social. In: NOVAES, R. R.; PORTO, M.; HENRIQUES, R. (Orgs.). Comunicações do ISER. ano 21. Edição especial, 2002. 
RÜDIGER, F. Introdução à teoria da comunicação. São Paulo: Edicom, 1998.

SODRÉ, M. Antropológica do espelho. Petrópolis: Vozes, 2002.

SOUZA, S. J. Dialogismo e alteridade na utilização da imagem técnica em pesquisa acadêmica: questões éticas e metodológicas. In: FREITAS, M. T.; SOUZA, S. J.; KRAMER, S. (Orgs.). Ciências humanas e pesquisa: leituras de Mikhail Bakhtin. São Paulo: Cortez, 2003.

VATTIMO, G. La sociedad transparente. Barcelona: Paidós, 1990.

Recebido em 16.03.09

Aprovado em 09.03.10

Eloiza Gurgel Pires, arte-educadora, artista plástica, doutoranda em Educação pela Universidade de Brasília - UnB, é professora da Secretaria de Estado de Educação do Distrito Federal. Suas pesquisas discutem as novas formas de produção de conhecimento na contemporaneidade a partir das relações entre arte, cultura, novos meios e educação. 